\title{
Medical.
}

\section{ThE Pathology OF MaLignant Disease OF THE LUNG AND PLEURA.}

By S. ROODHOUSE GLOYNE, M.D.LEEDS, D.P.H.

Pathologist, City of London Hospital for Diseases of the Heart and Lungs, Victoria Park.

WHEN the present writer began to make post-mortem examinations at Victoria Park twenty years ago, growths situated in the mediastinal glands were the type most commonly encountered; now the type affecting the lung itself with only secondary and often slight extension to the mediastinal glands, has come much more into the picture. Table I, recently published [I] from the post-mortem records of Victoria Park, illustrates these points.

\begin{tabular}{|c|c|c|c|c|}
\hline Years & $\begin{array}{l}\text { Total } \\
\text { number of } \\
\text { autopsies }\end{array}$ & $\begin{array}{c}\text { Number of } \\
\text { mediastinal } \\
\text { growths }\end{array}$ & $\begin{array}{l}\text { Number of } \\
\text { growths of lung } \\
\text { and pleura }\end{array}$ & Total grewths \\
\hline $\begin{array}{l}1904-13 \\
1920-29\end{array}$ & $\begin{array}{l}403 \\
670\end{array}$ & $\begin{array}{l}16\left(4^{\circ} 0 \text { per cent.) }\right. \\
3^{8}\left(5^{\circ} 7 \text { per cent. }\right.\end{array}$ & $\begin{array}{r}4 \text { (I } \circ \text { o per cent.) } \\
43 \text { (6.4 per cent.) }\end{array}$ & $\begin{array}{l}20(5.0 \text { per cent. }) \\
81(12.1 \text { per cent.) }\end{array}$ \\
\hline
\end{tabular}

Two points stand out: (I) There has been an increase in the number of malignan intrathoracic tumours coming to the post-mortem room, and (2) this increase has been mainly in the pulmonary group. Until quite recently the latter have been much the most difficult to diagnose, which may account to some extent for the ratio of the above figures.

In the absence of any adequate theory of ætiology of these growths, classification is largely a matter of personal bias. A classification based upon cellular structure is usually chosen, but anyone attempting it will be struck with the wide variation in the histological picture. As pointed out by Barnard [2] and Weller [3], growths vary from undifferentiated small round cell growths at one end of the scale to differentiated columnar, mucus-secreting and squamous cell growths at the other, while between the two extremes are growths of large polygonal and spheroidal cells, the so-called medullary growths. Probably nearly all are true carcinomata. A classification, in the present state of our knowledge, must be regarded very largely as simply an aid to description and diagnosis, for we see the cases much too late in the post-mortem room to determine exactly where the growths begin, whether in bronchial or alveolar epithelium or mucous glands, though there seems to be a general impression that the bronchi are the commonest sites of origin.

Malignant Disease of the Mediastinal Glands.

This was one of the earliest of the primary malignant neoplasms of the thorax to be described. One of the best recent accounts of its morbid anatomy is that of Hebert [4]. It is not often possible to say which group of the mediastinal glands is the first to be affected. The tumour is frequently soft and white, exuding a thin fluid like watered 
condensed milk, on section. Small hæmorrhages may be seen and some anthracosed patches. The capsule is ill-defined. Small areas of degeneration occur.

The tumour generally primarily affects the middle mediastinal glands; ultimately the disease extends to the whole of the mediastinum, but enlargement of the various divisions of the middle mediastinal group generally dominates the picture. As the glands enlarge they become adherent to each other, until finally they coalesce into a large, wide, irregular nodular collar of growth surrounding $(a)$ the lower end of the trachea, $(b)$ the two main bronchi, $(c)$ the pulmonary artery and its two main branches, $(d)$ the pulmonary veins, $(e)$ the superior vena cava and azygos major, and $(f)$ the first part and arch of the aorta. Also it may happen that the collar of growth, as it advances, presses on the left recurrent laryngeal nerve and on to the œsophagus, infiltrates outwards along the ramifications of the bronchi into one or both lungs, and may even penetrate the wall of the superior vena cava and pass down into the right auricle as a great shaggy vegetation. The picture may be summed up as one of compression, displacement, invasion and perforation of surrounding vital structures. Two forms of spread are described by Hebert, viz., diffuse and central, the first characterized by the growth forming deposits at irregular intervals as it spreads outwards, the second by a massive central growth, solid, firm, nodular and sharply defined, pressing on the surface of surrounding structures and only slowly extending outwards by continuity.

For many years neoplasms of this type were known as sarcomata (spindle-celled, oval-celled, mixed-celled, \&c.) or lymphosarcomata, but recently Barnard has pointed out that the oat-shaped cells which are one of their histological characteristics are present also in obvious true carcinomata, and that there is no essential difference between these tumours and true carcinomata. A bronchial origin is probable. Maxwell [5] suggests that the growths spring from the basal layer of bronchial mucosa. One of the most striking things is the wide variation in the histological picture which can be obtained in different sections taken from the same piece of tissue.

\section{Malignant Disease of the Bronchi.}

\section{(A) Single Nodule Growths.}

These growths, which are generally found in one of the main bronchi, vary in size from that of an acorn to that of a tangerine orange, and are of a yellowish brown colour. Perkins [6] believed that the starting point is probably frequently in the mucous glands of the bronchial wall. It may penetrate deeply into the bronchial wall or project into the lumen with a sloughing or bleeding surface, or papillomatous projections. Bronchiectasis is liable to occur, to be followed sooner or later by septic bronchopneumonia. Complete stenosis of the bronchus is not uncommon. Only rarely are secondary nodules found, and invasion of the mediastinal glands is by no means constant. Ulceration into the œesophagus may also occur.

Maxwell subdivides these tumours into four varieties : (I) A local tumour surrounding a main bronchus without obvious infiltration of either lung or mediastinum; (2) a tumour infiltrating the corresponding portion of the lung; (3) a tumour arising from a main bronchus and extending directly outwards into the mediastinal tissues; and (4) a tumour spreading into both lung and mediastinal tissues. 


\section{(B) Diffuse Bronchial Carcinomatosis.}

The outstanding characteristic of this variety is its resemblance to miliary tuberculosis of the lung ; indeed, it is sometimes referred to as miliary carcinomatosis. The minute carcinomatous nodules are of a dull, dirty, brownish-grey colour, are disseminated widely, tend to affect one lung only and to be often more marked at the base. The minute deposits of growth are slightly raised from the surface and are definitely in the bronchial wall. The deposits vary in shape with the angle at which the small bronchi have been divided. The cut end of the small bronchus is often closed with a small plug of growth. Miliary tubercles do not necessarily follow the line of the bronchioles, but when they do they arise in the peri-bronchial lymphatics rather than actually in the bronchial wall. They are discrete minute grey dots with healthy-looking areas between them and, when seen accompanying a bronchiole cut longitudinally, run in an interrupted line of dots like a Morse code signal. Furthermore, miliary tubercles generally exhibit differences in their various stages of evolution, some very small, pearly grey and translucent, others large, opaque and cheesy-looking. In miliary tubercle the mediastinal glands very rarely escape, whereas in carcinomatosis the infection of the glands is not so consistent, and when it occurs the glands do not display. the miliary-looking nodule as seen in the lung.

\section{Malignant Disease of the Lung.}

For convenience of description the growths may be divided into five groups :-

(I) Lower Lobe Growths. - These usually occupy the whole lobe, producing a completely solid lobe, and are yellow in colour with reddish-brown streaks here and? there due to hæmorrhage or minute obstructed vessels, and small grey or speckled black patches corresponding to collections of anthracosis pigment. The margins of the growth are unusually well-defined for a malignant tumour. When cut the surface of the tumour is generally rather granular and crumbles with the knife-quite different from the soapy consistence of a caseous lobe. Invasion of the pleura eventually occurs. The centre of the growth may break down to form a cavity with rough shaggy walls, villous-like processes projecting into it, and necrotic contents.

(2) Upper Lobe Growths. - Two special features may be emphasised here : (a) liability to break down and form cavities; $(b)$ special predilection for infection of tracheobronchial glands on the same side, which become firmly adherent to the trachea and the apical pleura, ultimately forming a thick cap of dense growth almost completely fused with the apex, and drawing the trachea away from the mid-line.

(3) Whole Lung Growths.-The following points should be noted: (a) Complete obliteration of interlobar fissures; $(b)$ filling up of the bronchi with plugs of growth so that the lung in cut section looks almost featureless, as though it had no bronchial system; $(c)$ less liability to cavity formation than other lobar forms ; $(d)$ pressure of the growth on pulmonary vessels. Secondary deposits may occur as small rounded discrete nodules in the other lung. Huguenin [7] has given a good description of these growths under the terms lobar and massive types of growth, stressing their remarkable "lobar systemization." He notes also how often the tumour resembles a testicle tumour, and may even have amyloid strands in it suggestive of syphilitic gummata-points to remember in differential diagnosis. He emphasizes, too, the soft necrotic pulpy character 
of some of the tumours, a characteristic which the present writer has found to be uncommon. Roubier [8] suggests that cavitation may result from: (I) necrosis and abscess formation; (2) breaking down of associated tuberculous disease of the lung; and (3) true cavitating carcinoma, a particular variety with a predilection for cavity formation described by the author as generally infecting the upper lobes, epitheliomatous in type, rarely producing metastases, and containing a purulent or fotid or blackish-grey thick fluid with shreds of growth in it.

(4) Multiple Nodules in Lung.-These are discrete yellowish nodules situated in one or more lobes of the lung, at any point in the parenchyma, varying in size from a small marble to a tangerine orange and looking very much like secondary nodules in the liver. There are two main reasons for placing them in a separate class : (1) At first sight they suggest secondary nodules; (2) when small they are liable to be confused with actinomycosis of the lung or lymphadenomatous deposits.

(5) Sclerotic Type.-Huguenin describes a massive fibrotic form of malignant growth in which the lung retracts against the mediastinum, suggesting to some writers a special histogenesis in which the sclerosis is presumed to have preceded the carcinoma ; but of this there appears to be little evidence. J. A. Miller and O. R. Jones mention a scirrhous type which is presumably the same as Huguenin's sclerotic type. They suggest that collapse of the lung with subsequent fibrosis may account for the scirrhous nature of the growth.

\section{Malignant Disease of the Pleura.}

Primary malignant growths of the pleura are rare. The account given by Roberts and Perkins [9] in 1909 still remains one of the best descriptions of the disease. Four different types can be distingushed:-

(I) General uniform infiltration of the pleura with much thickening producing a hard slow-growing tumour which ultimately encases the lung, a thick shell of growth sometimes penetrating into the interlobar fissure. The writer has known a false empyema to occur between the layers of this encasing growth.

(2) A form consisting of scattered nodules of growth in the pleura, probably merely a variety of the former.

(3) A form described by Roberts and Perkins as tuberiform, in which there are large pedunculated masses projecting from the surface into the pleural sac. Probably this is very rare.

(4) Endothelioma, a characteristic feature of which is that the whole serous membrane is simultaneously implicated. According to Roberts and Perkins the new growth forms a thin hard pellicle over the lung, more like a chronic pleurisy than a tumour, the undulated or trabeculated surface thus produced recalling the inner wall of a hypertrophied bladder.

Pleural effusion is common. Obliteration with adhesions and involvement of the parietal pleura are less common.

\section{Concealed Growths of Lung.}

Occasionally it happens that in examining histological sections of lungs in which there has been extensive suppuration, malignant disease is discovered which was not evident at the time of autopsy. These are generally cases of bronchiectasis, pulmonary 
abscess or gangrene. The commonest malignant lesions in these cases are those of diffuse bronchial carcinomatosis in which the carcinomatous deposits have been completely obscured by the bronchiectasis and general sepsis.

\section{New Growth and Tuberculosis in the same Lung.}

At least two forms occur. In the first the pathological picture may be predominantly that of neoplasm, but on close examination a few scattered tubercles are seen, generally at the apex or immediately beneath the pleura. Presumably they are obsolescent tubercles which have been awakened into mild degree of activity by the growth. Occasionally true calcareous nodules may be seen, generally subpleural in position (Ghon foci). In the second type there may be well-marked and fairly advanced active tuberculosis and neoplasm side by side. Thus, the writer has seen the typical upper lobe cavity of pulmonary tuberculosis, with an actively growing carcinoma in the lung tissue immediately beneath, encroaching on the lower wall of the tuberculous cavity.

\section{Special Pulmonary Complications of New Growths of Lung.}

The complications are generally due to sepsis. The commonest is bronchiectasis caused presumably by invasion of the bronchial tree by growth. Next in frequency as a complication may be mentioned pulmonary abscess, generally in the peripheral part of the lung and usually basal. False empyema between the layers of malignant pleura has already been mentioned. True empyema may also occur and may be encysted or interlobar, and can give rise to much confusion in diagnosis during life.

\section{Direct Extension to the Heart.}

The most direct route for the growth to follow is along the wall of the superior vena cava to the visceral pericardium and the right auricle, and prolongations of growth may even reach the right ventricle and the tricuspid valves. Warty or polypoid projections into the pericardial cavity are also described by Hebert. Extension to the parietal pericardium may follow.

Another form of extension to the heart is by way of invasion of the anterior superior mediastinal glands situated around the roots of the great vessels, occasionally giving the appearance of a pericardial growth. Extension to the left side is somewhat rare. If microscopical sections from various parts of the heart muscle be made, minute deposits of growth may occasionally be seen even when no naked-eye lesions of the heart are seen. Hebert describes these columns of growth spreading between the muscle fasciculi and isolating the outlying portions.

\section{REgIONAL LYMPH-GLANDS.}

In the majority of cases these are found to be infected. There is a marked tendency for the anterior superior mediastinal group of glands to be affected, whereas this group is only rarely affected in pulmonary tuberculosis. Direct extension upwards to the glands of the cervical chain may also occur, and also downwards through the posterior mediastinal glands to the abdominal lymph glands whence the growth may extend to the head of the pancreas. 


\section{Metastases.}

The commonest situations for metastases to occur are, in the order of frequency, osseous system (vertebræ, femur, ribs, sternum, skull, pelvic bones), liver, suprarenals, kidney, spleen, pancreas and brain, but of course practically no organ is immune from secondary deposits.

\section{Pleural Fluids Complicating Intrathoracic New Growths.}

Accumulation of fluid in the pleural cavity is a common complication. Sometimes it occurs late in the course of the disease; at others it arises in the early stages covering up the lung lesions and obscuring the diagnosis. It frequently recurs after paracentesis, but clears up presumably as a result of occlusion of the pleural cavity by growth. In I 3 I autopsies on intrathoracic malignant disease at Victoria Park between the years I9II and 1930, fluid was found in fifty-six instances [10].

The following types of fluid occurred.

\section{Serous Fluids.}

(I) Sterile effusions with no naked-eye lesions in the pleura, generally on same side as lung growth but occasionally on opposite.

(2) Effusions with secondary deposits in the pleura.

(3) Localized "pocketed" effusions.

(4) Clear effusions with secondary bronchiectasis beneath.

(5) Clear Fluids Secondarily Infected.-The bacterial flora is mixed-streptococci, staphylococci, fusiform bacilli, \&c.

(6) Effusions containing Tubercle Bacilli.-It is not very uncommon to find ? pulmonary tuberculosis and malignant disease in the same lung, but it is less common to find a serous effusion containing tubercle bacilli as a complication of new growth. The writer has only seen two cases.

(7) Effusions subsequently Replaced by Adhesions and Growth.-This seems to be worth commenting upon because it is sometimes stated that the absorption of a pleural effusion negatives a diagnosis of new growth, but such is by no means always the case. At first sight it may seem unlikely that absorption of fluid can take place through a visceral pleura studded with growth, but it is probable that the absorption is effected through the parietal pleura.

(8) Effusions possibly Related to Treatment.-Two varieties occurred, viz., cases in which effusion was associated with $(a)$ artificial pneumothorax, and $(b)$ the insertion of radon needles. Serous fluids may possibly be accounted for in one of two ways, viz., either there were minute subpleural deposits of growth not visible to the naked eye, or pressure of the growth in the mediastinum caused interference with lymphatic drainage or venous return. Hæmorrhages into fluids may occur. Pure hæmothorax is very rare. It is rather surprising that with the many possibilities of venous and lymphatic obstruction secondary infection of serous fluids is not commoner.

\section{Purulent Fluids.}

(I) Empyema.-Often associated with secondary bronchiectasis in the malignant lung beneath. The empyema may be interlobar, or may be divided into two separate cavities by means of a sheet of adhesions. 
(2) Pyopneumothorax with a Mixed Bacterial Flora.

(3) Pus from Bronehiectatic Cavities.-Bronchiectasis is a common complication of malignant disease of the lung, especially in cases in which there is involvement of the bronchus with growth. If the bronchiectatic cavity be of considerable size the exploring needle may enter it and withdraw pus, which gives rise to the belief that an empyema is present. The writer has seen five such instances. In four of them a rib resection operation had been done and the wound had failed to heal.

\section{Differential Diagnosis.}

As far as the pathologist is concerned differential diagnosis during life rests with examination of $(a)$ sputum and portions of lung tissue coughed up ; $(b)$ portions of lung tissue removed by bronchoscope; $(c)$ pleural effusions; $(d)$ Wassermann reaction.

With regard to sputum there is little to say. Occasionally, plaques of degenerated endothelial cells give a hint as to the diagnosis, but there is nothing pathognomonic. Portions of tissue must be large enough to permit of histological section, when occasionally the growth picture can be identified. The same remark applies to portions of growth removed by bronchoscope. In pleural effusions complicating malignant disease the following points are important: (I) Specific gravity of about I,o18; (2) a protein content of not more than 3.5 per cent.; (3) cell count in which large numbers of endothelial cells in all stages of degeneration and vacuolation (including the "signet ring" form with the nucleus contracted down to one side of the cell) play a predominant part (4) sterility on culture media. Occasionally also the cell picture shows a high percentage of eosinophil leucocytes. Unfortunately, however, malignant cells cannot be identifiedo with certainty. With regard to the Wassermann reaction, it is important to bear in mind that a positive Wassermann reaction does not necessarily negative a diagnosis of neoplasm. If the clinician has good reason for accepting a diagnosis of neoplasm, he should not be put off by the fact of a positive Wassermann reaction.

In the post-mortem room differential diagnosis generally rests between miliary tubercle, actinomyces, gummata, and, very rarely, fibrosis of the lung and bronchiectasis. Enough has already been said in the early parts of this paper to indicate the main lines of differentiation.

\section{REFERENCES.}

[1] Gloyne, S. Roodhouse. Tubercle, 1930, xii, 54.

[2] BARNARD. Journ. of Path. and Bact., 1926, xxix, 241.

[3] Weller, C. V. Journ. of Cancer Research, 1929, xiii, 218.

[4] Hebert, G. T. Quart. Journ. Med., 1918, xi, 165.

[5] Maxwell, J. Journ. Path. and Bact., 1930, xxxiii, 233.

[6] Perkins, J. J. Allbutt and Rolleston's "System of Medicine," 1909, vol. v.

[7] Huguenin, R. "Le Cancer primitif du Poumon," Paris, 1928.

[8] Roubier, Сн. Journ. de Méd. de Lyon, 1929, x, 615.

[9] Roberts, F. T., and Perkins, J. J. Allbutt and Rolleston's "System of Medicine," 1909, vol.v.

[10] Gloyne, S. Roodhouse. Lancet, 1931, i, 294. 